\title{
Studi Kestabilan Lereng Alam Tambang Terbuka (Studi kasus: lereng tambang batu kapur Lamongan dan Madura)
}

\author{
Mohammad Muntaha \\ Program Studi Diploma Teknik Sipil FTSP ITS \\ Email:mohamad_m74@ce.its.ac.id
}

\begin{abstract}
The fact that East Java's geological structure is made up of Mountainous Zone, Kendeng Zone, and Apex Zone (Zona Rembang) is the reason why the topography of this region is formed by limestone, volcanic rock, and the often times found karst. Based on the structure of the soil, this geological structure cannot be used for productions such as farming, agriculture, etc. That's why people use these areas for community mining. In an open limestone mining, especially one managed by the community, slope design and its stability is often not analyzed, even though the problem of slope stability in an open mine is a very important issue because it is related to human safety, mining equipment, and other infrastructure located around the slopes of the excavation site.

The purpose of this study is to measure physical (moisture, volume weight, gravity specification), and mechanical (Unconfined Compressive Strength test, Point Load test, and Wear and Tear Test) of rock characteristics. Test results of physical and mechanical characteristics will be used for excavation stability analysis (calculation of security), which in this analysis there are variation of slope and dynamic vibration (due to the dynamic load of the vehicle) with the help of Plaxis program.

The results show that in terms of rock density, rocks located in Lamongan are denser than rocks located in Madura; in terms of the pore, Lamongan rocks are smaller than Madura rocks. As for the results of excavation stability analysis of mining sites in Madura, safe condition is achieved when the mining height is $\mathrm{H} 10 \mathrm{~m}$ with maximum angle of $50^{\circ}$ and if the mining height is $\mathrm{H} 20 \mathrm{~m}$, the maximum angle is $30^{\circ}$. In Lamongan, safe condition is achieved for the entire excavation conditions; from $\mathrm{H} 10$ $m$ up to $\mathrm{H} 45 \mathrm{~m}$ with excavation angle $30^{\circ}$ up to $90^{\circ}$.
\end{abstract}

Keywords: slope stability, open pit lime stone, physics and mechanics properties, cohesion, internal friction angle, GEO-SLOPE.

\begin{abstract}
Abstrak
Struktur geologi wilayah Jawa Timur yang tersusun atas Zona Pegunungan, Zona Kendeng, dan Zona Rembang menyebabkan wilayah ini memiliki topografi yang terbentuk oleh batu gamping, batu vulkanik, dan sering dijumpai karst. Secara struktur tanah dengan struktur geologi seperti ini tidak dapat digunakan untuk kegiatan produksi seperti perkebunan, pertanian, dll. Sehingga masyarakat menggunakan wilayah ini untuk pertambangan rakyat. Dalam penambangan kapur terbuka khususnya penambangan yang dikelola oleh masyarakat, desain lereng dan kestabilannya seringkali tidak dianalisa, padahal masalah kestabilan lereng pada suatu tambang terbuka merupakan masalah yang sangat penting karena menyangkut masalah keselamatan manusia, peralatan penambangan, dan infrastruktur lainnya yang berada disekitar lereng galian.

Tujuan penelitian ini adalah mengukur karakteristik fisik (kadar air, berat volume, spesifik gravity), dan mekanis batuan (pengujian Unconfined Compressive Strength, Tes Point Load, dan Uji Keausan). Hasil uji karakteristik fisik dan mekanis akan digunakan untuk analisa kestabilan galian (perhitungan angka keamanan), dimana dalam analisa ini dilakukan variasi kemiringan lereng dan getaran dinamis (akibat beban dinamis kendaraan) dengan menggunakan bantuan program Plaxis.

Hasil pengujian menunjukkan bahwa dari segi kepadatan batuan, batuan lokasi Lamongan lebih padat daripada batuan di lokasi Madura; demikian juga dari segi angka pori, batuan Lamongan lebih kecil daripada batuan Madura. Hasil analisa stabilitas galian lokasi penambangan, untuk lokasi Madura, kondisi aman dicapai apabila pertambangan setinggi $\mathbf{H} 10 \mathrm{~m}$, maksimal sudut galian adalah $50^{\circ}$ dan apabila pertambangan setinggi $\mathrm{H} 20 \mathrm{~m}$, maksimal sudut galian adalah $30^{\circ}$. Untuk lokasi Lamongan, kondisi aman dicapai untuk seluruh kondisi penggalian, baik $\mathrm{H} 10 \mathrm{~m}$ s/d

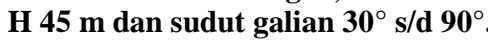

Kata kunci: kestabilan lereng, penambangan kapur terbuka, sifat fisik dan mekanis, kohesi, GEO-SLOPE. 


\section{Pendahuluan}

Struktur geologi tanah Propinsi Jawa Timur sebelah utara didominasi oleh batuan karst dan batuan kapur. Sehingga di wilayah kabupaten Tuban, Lamongan, Gresik, Bangkalan, dan Jember banyak memiliki pegunungan kapur. Adanya batuan kapur di wilayah tersebut ikut mempengaruhi sosial dan budaya dalam kehidupan masyarakat sekitar, banyak sekali dilakukan penambangan batu kapur oleh masyarakat di wilayah-wilayah ini.

Permasalahan utama tambang rakyat adalah berupa tambang terbuka serta tanpa perencanaan, sehingga banyak dijumpai kerusakan lingkungan dan kelongsoran pada tambang. Dalam penambangan terbuka, disain kestabilan lereng merupakan salah satu permasalahan dan tantangan utama dalam setiap perancangan dan operasi penambangan. Hal tersebut memerlukan pengetahuan yang khusus tentang parameter atau karakteristik batuan yang seringkali sangat kompleks dan bervariasi. Pemahaman aspek praktis dalam implementasi desain juga dibutuhkan (Wyllie, 2004). Tingkat kestabilan pada lereng sangat penting dipastikan dalam penambangan terbuka untuk meminimalkan resiko yang berhubungan dengan keselamatan tenaga kerja, keamanan peralatan, serta resiko ekonomi yaitu cadangan/deposit galian tambang. Untuk itu pemahaman yang konprehensif mulai dari karakteristik fisik, mekanis, dan dinamis dari material batuan sampai dengan perilaku kelongsorannya menjadi penting untuk dilakukan.
Untuk itu telah dilakukan sejumlah pengujian terhadap batu kapur dari Kabupaten Lamongan dan Pulau Madura, pada masing-masing lokasi diuji karakteristik fisik dan mekanik batuan. Sample batuan diambil pada kedalaman -1 meter sampai -3 meter pada lereng galian pertambangan. Hasil pengujian karakteristik fisik dan mekanik digunakan untuk evaluasi kondisi kestabilan galian pertambangan yang selama ini dilaksanakan sehingga kelongsoran badan galian di penambangan terbuka batu kapur dapat dihindari.

\section{Metodologi}

Penelitian yang telah dilakukan merupakan serangkaian pengujian di laboratorium dan lapangan. Pengujian lapangan berupa pengeboran dan pengambilan sampel batuan. Penelitian laboratorium yang dilakukan adalah serangkaian kegiatan pengujian sifat fisik batuan dan uji sifat mekanik. Bahan sample yang diuji berupa batu kapur yang diambil dari daerah lereng pegunungan wilayah Kabupaten Lamongan (Kec. Babat) dan Kabupaten Bangkalan (Kec. Socah). Batuan yang diambil adalah bagian permukaan, yakni pada kedalaman 0 - 3 meter. Pengujian kadar air, berat volume, dan spesifik gravity menggunakan standar pengujian tanah, dari hasil pengujian ini kemudian dapat ditentukan derajat kejenuhan, berat volume kering batuan, angka pori, dan porositas. Pengujian sifat mekanik menggunakan tes Versa dan tes Point Load. 
Untuk mengetahui perubahan angka keamanan pada lereng tambang pada berbagai kemiringan lereng dan pengaruh beban luar dilakukan simulasi lereng. Untuk memudahkan perhitungan simulasi lereng dipakai program bantu Plaxis dan lereng dimodelkan dengan kemiringan $30^{\circ}, 50^{\circ}, 70^{\circ}$, dan $90^{\circ}$. Untuk masing-masing kemiringan lereng dibuat enam variasi tinggi lereng yaitu 10 meter, 20 meter, 25 meter, 30 meter, 40 meter, dan 45 meter.

\section{Hasil dan Pembahasan}

\subsection{Hasil Pengujian Gravol}

Pengujian gravimetri dan volumetri dilakukan pada benda uji pada lokasi studi pada kedalaman -1 m sampai kedalaman $-3 \mathrm{~m}$. Hasil penelitian berat volume, angka pori, dan spesifik gravity batuan kapur dari Lamongan dan Madura seperti terlihat pada Tabel 1 . Berdasarkan hasil pengujian tersebut terlihat bahwa batu kapur Lamongan ini terlihat dari nilai berat volume dan mempunyai kepadatan yang lebih baik dibandingkan batu kapur Madura, hal spesifik gravity batuan. Dari Tabel 1 juga terlihat nilai spesifik gravity, berat volume cenderung naik seiring kedalaman, sedangkan dan kadar air dan angka pori cenderung berkurang.

\subsection{Hasil Pengujian Sifat Mekanis}

Untuk mengetahui sifat mekanis batuan dilakukan dengan pengujian beban terpusat, dari uji ini akan didapatkan besarnya indeks kekuatan batuan. Untuk melihat kekuatan batuan juga diuji indeks keausan batuan. Hasil pengujian unconfined compression test batuan berupa tegangan dan kuat tekan pada lokasi studi Lamongan dan Madura seperti terlihat pada Tabel 1. Gambar 1 menunjukkan pengujian Batuan di laboratorium.

Tabel 1. Hasil Pengujuan Batuan Kapur dari Lamongan dan Madura

\begin{tabular}{lccccccc}
\hline \multirow{2}{*}{ Jenis Pengujian } & \multirow{2}{*}{ Satuan } & \multicolumn{3}{c}{ Batuan Lamongan } & \multicolumn{3}{c}{ Batuan Madura } \\
\cline { 3 - 8 } & & $0,5-1,0$ & $1,5-2,0$ & $2,5-3,0$ & $0,5-1,0$ & $1,5-2,0$ & $2,5-3,0$ \\
\hline Volgrav & & 2,402 & 2,483 & 2,412 & 2,375 & 2,286 & 2,405 \\
\hline $\mathrm{G}_{\mathrm{s}}$ & $\%$ & 21,05 & 24,73 & 23,41 & 45,12 & 30,08 & 24,16 \\
$\mathrm{~W}_{\mathrm{c}}$ & $\mathrm{t} / \mathrm{m}^{3}$ & 1,765 & 1,805 & 1,835 & 1,605 & 1,652 & 1,831 \\
$\partial_{\mathrm{t}}$ & $\mathrm{t} / \mathrm{m}^{3}$ & 1,42 & 1,45 & 1,49 & 1,37 & 1,34 & 1,44 \\
$\partial_{\mathrm{d}}$ & & 0,69 & 0,58 & 0,67 & 1,15 & 0,73 & 0,62 \\
$\mathrm{e}$ & $\%$ & 75,28 & 95,48 & 92,21 & 93,15 & 97,58 & 96,29 \\
$\mathrm{~S}_{\mathrm{r}}$ & & & & & & & \\
\hline Mekanik & $\mathrm{kg} / \mathrm{cm}^{2}$ & 5,21 & 21,85 & 10,12 & 6,75 & 2,16 & 6,23 \\
\hline$\sigma_{1}$ & $\mathrm{~kg}$ & 30,5 & 285,3 & 114,2 & 55,1 & 12,6 & 82,5 \\
UCS, P & $\%$ & 55 & 89 & 85 & 80 & 45 & 75 \\
Indeks Keausan & & & & & & & \\
\hline
\end{tabular}

Sumber: hasil pengujian 
Dari Tabel 1 terlihat bahwa tegangan, $\sigma_{1}$ untuk lokasi Madura lebih kecil daripada lokasi Lamongan. Hal ini menunjukkan bahwa besarnya rasio antara kuat tekan dengan luas bidang permukaan yang tertekan untuk batuan lokasi Madura lebih kecil daripada lokasi Lamongan. Nilai rata-rata tegangan, $\sigma_{1}$ batuan untuk lokasi Lamongan adalah $16,99 \mathrm{~kg} / \mathrm{cm}^{2}$, sedangkan lokasi Madura adalah $14,76 \mathrm{~kg} / \mathrm{cm}^{2}$.

Dari Tabel 1 juga terlihat bahwa kuat tekan, $\mathrm{P}$ untuk lokasi Madura lebih kecil daripada lokasi Lamongan. Nilai rata-rata kuat tekan, $\mathrm{P}$ batuan untuk lokasi Lamongan adalah 188,67 kg, sedangkan lokasi Madura adalah 187,33 kg.

\subsection{Hasil Pemodelan Pembebanan}

\subsubsection{Asumsi Pemodelan Lereng}

Untuk melihat pengaruh penambangan, yaitu berupa penggalian, beban kendaraan, dibuat pemodelan untuk mendapatkan variasi perubahan angka keamanan. Pemodelan ini menitikberatkan kepada pengaruh beban statis dan dinamis kendaraan terhadap kestabilan lereng pertambangan batu kapur di ke dua lokasi studi. Dimensi galian pertambangan yang direncanakan berukuran 100 m x 100 m dengan asumsi bahwa tidak dilakukan perkuatan pada tepi bidang galian tambang. Gambaran kondisi permodelan galian tambang kapur seperti terlihat pada Gambar 2.

Adapun asumsi-asumsi yang digunakan dalam pemodelan ini adalah:

a. Asumsi kondisi lereng batuan adalah homogen dan tanpa retakan. (homogenitas $=$ sifat karakteristik fisis dan mekanis batuan pada area penambangan adalah sama, baik pada permukaan maupun sampai sisi dasar galian).

b. Variasi Kemiringan galian, $\alpha\left(30^{\circ}\right.$, $50^{0}, 70^{\circ}, 90^{\circ}$ )

c. Variasi Ketinggian galian, H (10, $20 \mathrm{~m}, 25 \mathrm{~m}, 30 \mathrm{~m}, 40 \mathrm{~m}, 45 \mathrm{~m}$ ).

d. Variasi jarak antara bibir galian dengan beban kendaraan adalah 1 meter, 2 meter, dan 3 meter.

e. Beban kendaraan kondisi dengan muatan diasumsikan sebesar 12,32 ton.

\subsubsection{Hasil Perhitungan Stabilitas}

Untuk melihat kestabilan lereng pada lokasi studi maka perlu dilakukan perhitungan angka keamanan (safety factor) sehingga dapat dikatagorikan apakah lereng tersebut aman, kritis atau berpotensi longsor. Maka pemodelan numerik perlu dilakukan untuk perhitungan angka keamanan lereng atau kestabilan galian pertambangan, yaitu dengan menggunakan program bantu Plaxis. Plaxis digunakan untuk melihat deformasi dan angka keamanan pada batuan akibat beban statis maupun dinamis. Beban kendaraan dalam pemodelan Plaxis dijadikan beban terpusat, dengan asumsi kendaraan berhenti/parkir ditepi galian dengan jarak antar kendaraan 1 meter. Jika ditinjau dari pemodelan ini, kendaraan berjajar searah tegak lurus bidang gambar. Diketahui beban kendaraan beserta muatannya adalah 12,32 ton, prosentase pembagian beban untuk jenis truk adalah $40 \%$ diterima roda depan dan $60 \%$ diterima roda belakang. 
Output atau keluaran yang dihasilkan dalam program Plaxis 2D versi 2011 adalah deformasi batuan (akibat beban statis dan dinamis) dan safety factor (akibat beban statis dan dinamis) yang dalam hal ini merupakan faktor keamanan galian pertambangan. Rentang aman stabilitas sebuah galian pertambangan adalah apabila memiliki safety factor di atas 1.00. Beberapa perhitungan menunjukkan hasil "collapsed" atau dalam keadaan bahaya, hal ini disebabkan terlampauinya daya dukung batuan di sekitar proyek pertambangan. Tabel-tabel berikut ini menunjukkan hasil perhitungan numerik yang disajikan pada lokasi Kab. Lamongan dan Pulau Madura.

Dari Tabel 1 dan Tabel 2 terlihat bahwa nilai angka keamanan stabilitas galian pada kemiringan galian $30^{\circ}$ dengan asumsi pembebanan adalah beban kendaraan sebesar 12,32 ton, jarak kendaraan dari tepi galian adalah 1 meter untuk wilayah Kab. Lamongan dinyatakan aman sampai kedalaman galian 25 meter. Untuk wilayah Pulau Madura dinyatakan aman sampai kedalaman galian 20 meter. Untuk kemiringan galian $50^{\circ}$ dengan asumsi pembebanan yang sama lokasi Kab. Lamongan dinyatakan aman sampai kedalaman galian 25 meter, sedangkan stabilitas galian untuk wilayah Pulau Madura dinyatakan aman sampai kedalaman galian 10 meter.

Dari Tabel 3 dan Tabel 4 terlihat bahwa nilai angka keamanan stabilitas galian pada kemiringan galian $30^{\circ}$ dengan asumsi pembebanan adalah beban ken- daraan sebesar 12,32 ton, jarak kendaraan dari tepi galian adalah 2 meter untuk lokasi wilayah Kab. Lamongan dinyatakan aman sampai kedalaman galian 25 meter. Untuk wilayah Pulau Madura dinyatakan aman sampai kedalaman galian 20 meter. Untuk galian pada kemiringan galian $50^{\circ}$ dengan asumsi pembebanan untuk wilayah Kab. Lamongan dinyatakan aman sampai kedalaman galian 25 meter, untuk wilayah Pulau Madura dinyatakan aman sampai kedalaman galian 10 meter. Apabila galian pada kemiringan galian $70^{\circ}$ dengan asumsi pembebanan yang sama untuk wilayah Kab. Lamongan dinyatakan aman sampai kedalaman galian 5 meter. Sedangkan stabilitas galian untuk wilayah Pulau Madura dinyatakan tidak aman sejak awal penggalian.

\section{Simpulan}

Dari hasil analisa dapat disimpulkan sebagai berikut:

1. Hasil pengujian fisik batuan, terlihat kepadatan batuan, batuan lokasi Lamongan lebih padat $\left(\gamma_{\mathrm{t}}=2,443\right.$ $\mathrm{t} / \mathrm{m}^{3}$ ) daripada batuan di lokasi Madura. Dari segi kemampuan menyerap air, batuan Madura lebih jenuh air $\left(\mathrm{S}_{\mathrm{r}}=94,266 \%\right)$ daripada batuan Gresik $\left(S_{\mathrm{r}}=75,032 \%\right)$. Dari segi porositas, batuan Madura memiliki pori-pori rerata yang lebih besar $(\mathrm{e}=1,133)$ daripada batuan Lamongan $(e=0,670)$.

2. Hasil pengujian kuat tekan rata-rata batuan terlihat kuat tekan rata-rata batuan Madura $\left(\mathrm{q}_{\mathrm{u}}=14,759 \mathrm{~kg} / \mathrm{cm}^{2}\right)$, 
dan kekuatan tekan rata-rata batuan Lamongan $\left(\mathrm{q}_{\mathrm{u}}=16,996 \mathrm{~kg} / \mathrm{cm}^{2}\right)$.

3. Dari hasil pengujian tingkat keausan batuan dengan menggunakan slaking test, dapat disimpulkan bahwa ting- kat keausan rata-rata batuan Madura (Medium High Durability) lebih tinggi daripada tingkat keausan batuan Gresik (Medium Durability).

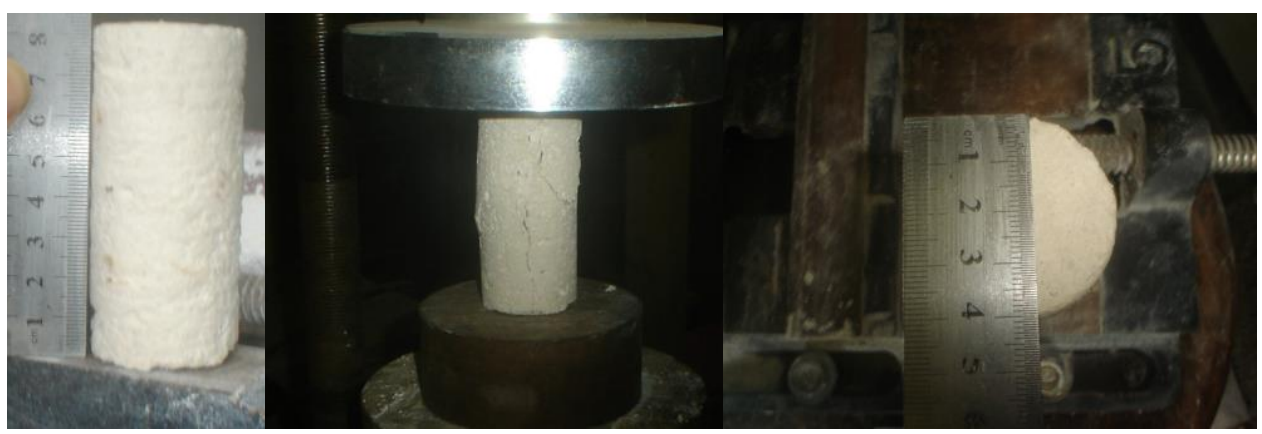

Gambar 1. Foto pengujian tes tekan UCS di laboratorium

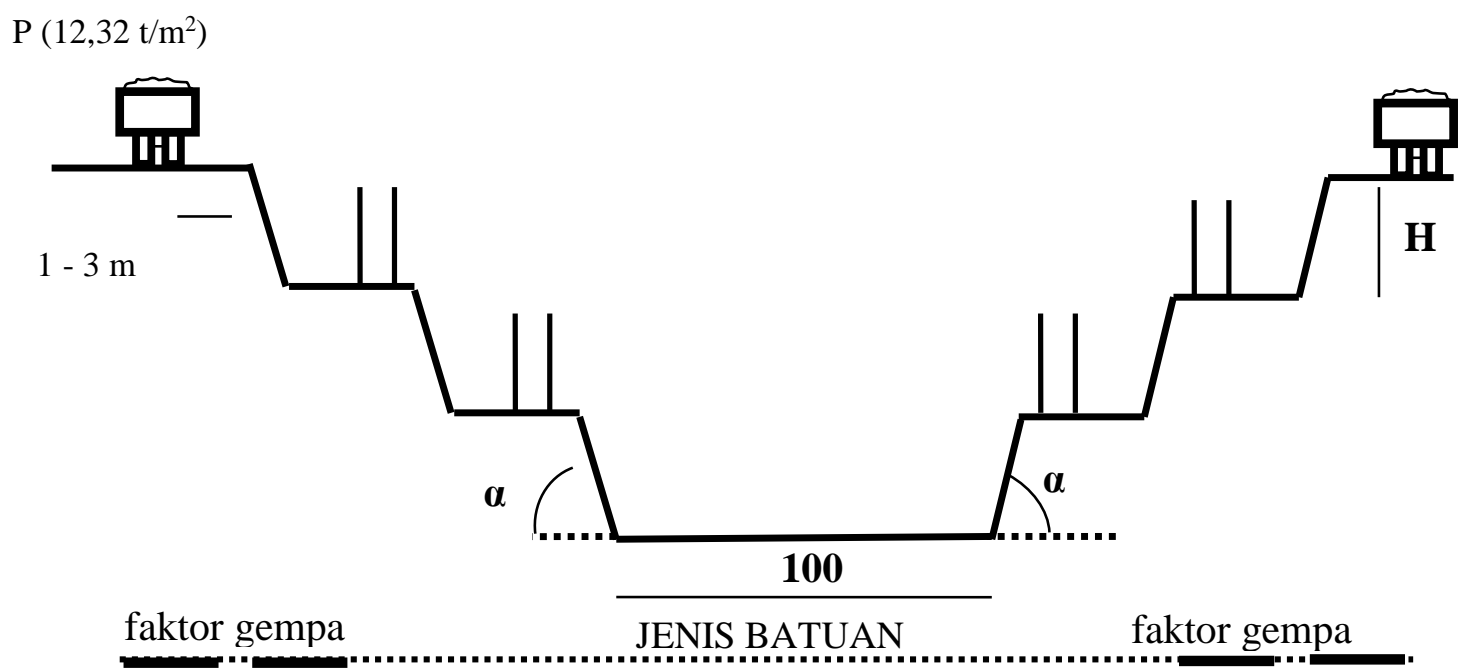

Gambar 2. Ilustrasi pemodelan dalam analisa kestabilan galian pada area penambangan

Tabel 1. Nilai angka keamanan (SF) dengan asumsi kendaraan kondisi bermuatan penuh, jarak kendaraan dari galian adalah 1 meter untuk lokasi Lamongan.

\begin{tabular}{lllll}
\hline \multirow{2}{*}{$\begin{array}{c}\text { Tinggi galian } \\
(\mathrm{m})\end{array}$} & \multicolumn{4}{c}{ Angka keamanan $(\mathrm{SF})$} \\
\cline { 2 - 5 } & 30 & 50 & 70 & 90 \\
\hline 10 & 1.72 & 1.49 & 1.17 & 0.75 \\
20 & 1.24 & 1.12 & 0.85 & 0.7 \\
25 & 1.05 & 1.05 & 0.84 & 0.61 \\
30 & 0.91 & 0.88 & 0.79 & 0.59 \\
40 & 0.79 & 0.77 & 0.76 & 0.55 \\
45 & 0.73 & 0.74 & 0.72 & 0.53 \\
\hline
\end{tabular}




\section{ISSN.1907-753X}

Tabel 2. Nilai angka keamanan (SF) dengan asumsi kendaraan kondisi bermuatan penuh, jarak kendaraan dari galian adalah 1 meter untuk lokasi Madura.

\begin{tabular}{lllll}
\hline \multirow{2}{*}{$\begin{array}{c}\text { Tinggi galian } \\
(\mathrm{m})\end{array}$} & \multicolumn{5}{c}{ Angka keamanan (SF) } \\
\cline { 2 - 6 } & \multicolumn{5}{c}{30} & \multicolumn{4}{c}{ Sudut kemiringan galian, $\alpha\left(^{\circ}\right)$} \\
\hline 10 & 1.72 & 1.5 & 1.18 & 0.77 \\
20 & 1.24 & 1.12 & 0.85 & 0.71 \\
25 & 1.06 & 1.05 & 0.84 & 0.61 \\
30 & 0.92 & 0.88 & 0.8 & 0.6 \\
40 & 0.78 & 0.78 & 0.77 & 0.55 \\
45 & 0.74 & 0.74 & 0.72 & 0.53 \\
\hline
\end{tabular}

Tabel 3. Nilai angka keamanan (SF) dengan asumsi kendaraan kondisi bermuatan penuh, jarak kendaraan dari galian adalah 2 meter untuk lokasi Lamongan.

\begin{tabular}{lllll}
\hline \multirow{2}{*}{$\begin{array}{l}\text { Tinggi galian } \\
(\mathrm{m})\end{array}$} & \multicolumn{4}{l}{ Angka keamanan $(\mathrm{SF})$} \\
\cline { 2 - 5 } & \multicolumn{4}{l}{ Sudut kemiringan galian, $\alpha\left(^{\circ}\right)$} \\
\hline 10 & 1.41 & 50 & 70 & 90 \\
\cline { 2 - 5 } 20 & 1.02 & 0.86 & 0.93 & 0.57 \\
25 & 0.87 & 0.73 & 0.68 & 0.47 \\
30 & 0.76 & 0.72 & 0.66 & 0.45 \\
40 & 0.66 & 0.63 & 0.62 & 0.44 \\
45 & 0.61 & 0.6 & 0.59 & 0.39 \\
\hline
\end{tabular}

Tabel 4. Nilai angka keamanan (SF) dengan asumsi kendaraan kondisi bermuatan penuh, jarak kendaraan dari galian adalah 2 meter untuk lokasi Madura.

\begin{tabular}{lllll}
\hline \multirow{2}{*}{$\begin{array}{l}\text { Tinggi galian } \\
(\mathrm{m})\end{array}$} & \multicolumn{4}{l}{ Angka keamanan $(\mathrm{SF})$} \\
\cline { 2 - 5 } & \multicolumn{4}{l}{ Sudut kemiringan galian, $\alpha\left(^{\circ}\right)$} \\
\cline { 2 - 5 } & 30 & 50 & 70 & 90 \\
\hline 10 & 1.41 & 1.22 & 0.97 & 0.6 \\
20 & 1.02 & 0.9 & 0.78 & 0.57 \\
25 & 0.87 & 0.86 & 0.72 & 0.55 \\
30 & 0.76 & 0.75 & 0.68 & 0.53 \\
40 & 0.66 & 0.65 & 0.58 & 0.43 \\
45 & 0.61 & 0.6 & 0.57 & 0.44 \\
\hline
\end{tabular}

4. Untuk lokasi Lamongan, stabilitas ketinggian galian $\mathrm{H}=10 \mathrm{~m}$ dapat dicapai apabila sudut kemiringan dinding galian $(\alpha) \max .70^{\circ}$; stabilitas ketinggian galian $\mathrm{H}=20 \mathrm{~m}$ dapat dicapai apabila sudut kemiringan dinding galian $(\alpha) \max .50^{\circ}$ dan $30^{\circ}$; untuk ketinggian galian $\mathrm{H} \geq 30 \mathrm{~m}$, kondisi stabilitas tidak dapat dicapai walaupun dengan sudut kemiringan ( $\alpha$ ) $30^{\circ}$ sampai dengan $90^{\circ}$. 
5. Untuk lokasi Madura, stabilitas ketinggian galian $\mathrm{H}=10 \mathrm{~m}$ dapat dicapai apabila sudut kemiringan dinding galian $(\alpha) \max .50^{\circ}$; stabilitas ketinggian galian $\mathrm{H}=15 \mathrm{~m}$ dapat dicapai apabila sudut kemiringan dinding galian $(\alpha) \max .30^{\circ}$; untuk ketinggian galian $\mathrm{H} \geq 25 \mathrm{~m}$, kondisi stabilitas tidak dapat dicapai walaupun dengan sudut kemiringan

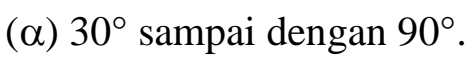

\section{Daftar Pustaka}

Abramson, Lee. W, Thomas S.Lee, Sunil Sharma, Glenn M. Boyce., 1. Slope Stability and Stabilization methods, John Wiley \& Sons, Inc., New York.

Bowles, J.E., 1984. Physical and Geotechnical Properties of Soils, McGraw-Hill Inc., USA.

Hartman, H.L., 1987. Introductory Mining Engineering, Willey, New York.

Terzaghi, Karl dan Ralph B. Peck. 1993. Mekanika Tanah dalam Praktek Rekayasa. Jakarta: Erlangga.

Kliche, C.A, 1999. Rock Slope Stability, Society for mining, Metallurgy, and Exploration, Inc (SME), USA.

Terzaghi, K. and Peck, R.B., 1948. Soil Mechanics in Engineering Practice, Wiley, New York.

Wyllie, D.C., and Christopher W. Mah, 2004. Rock slope engineering: civil and mining, $4^{\text {th }}$ edition, Spon Press is an imprint of the Taylor \& Francis Group, New York.
Waltham, A.C., 1994. Foundations Of Engineering Geology, Civil Engineering Department Nottingham Trent University, New York. 